\title{
The problem of artistic image creating in the process of a teacher artist training
}

\author{
V.A. Vardanyan $^{1 *}$, S.V. Shishkina ${ }^{2}$, and N.V. Matveeva ${ }^{3}$ \\ ${ }^{1}$ Mordovian State Pedagogical University named after M.E. Evsevyev, Saransk, Russia \\ ${ }^{2}$ Mordovian State Pedagogical University named after M.E. Evsevyev, Saransk, Russia \\ ${ }^{3}$ Mordovian State Pedagogical University named after M.E. Evsevyev, Saransk, Russia
}

\begin{abstract}
The article deals with the problem of artistic image creating in the students' creative works as a productive source of an artisticpedagogical development of the future teacher artist. An artistic image is the basis of any art form and occupies the leading part in the artwork as it has a vast and significant esthetic value, demonstrating the result of an artist life experience display. The analysis of the theoretical sources, university training internship and the process of creative works fulfillment in different art forms brought to light the undervaluation of the necessity of scientifically grounded pedagogical grounds creation which will allow to the utmost prepare the students to the artistic image creating. This determines the relevance of the ways developing of students' readiness to create an artistic image and its implementation in creative activities.
\end{abstract}

\section{A problem statement}

An artistic image is the basis of any art form and occupies the leading part in the artwork as it has a vast and significant esthetic value, demonstrating the result of an artist life experience display. Realizing their thoughts and feelings through the image of objects or phenomena, the artist creates a work of art.

Children art schools, being the initial units in the system of art education, are focused on the formation of the basics of visual literacy among students, which is important in the future when studying in secondary professional and higher educational institutions. The analysis of the educational training of art schools and the university process of art disciplines training revealed the lack of scientifically-based pedagogical conditions that allow students to prepare as much as possible to create an artistic image in the process of performing creative works.

Thus we found the contradiction between the necessity of the artistic image creating in the creative works on painting, drawing, decorative and applied art and insufficient readiness of students to create an expressive artistic image, which arises largely as a result of the spontaneous implementation of this process without sufficient and purposeful pedagogical guidance. The above mentioned contradiction signifies the relevance of the

\footnotetext{
*Corresponding author: prof-ped.gpa@mail.ru
} 
problem under study, which consists in finding and determining effective pedagogical conditions for the formation of the readiness of future teacher-artists to create an artistic image in the creative activity.

\subsection{The objective of the work}

The category «artistic image» is one of the ground-braking categories in the theory of art and is inextricably linked to such a universal concept as culture. E.N. Shapinskaya and N.I. Kiyashchenko consider that the process of artistic image perception is influenced by personal associations and personal qualities of each person, so it is impossible to talk about the unambiguous nature of the artistic image [1]. L.V. Chernets, considering the concept of "artistic image", notes its importance «as an art criticism term and the polysemy of the image in philosophical terms» [2].

G.N. Pospelov divides the images into « artistic, scientific-illustrative and factual (telling about various facts)»[3]. B.P. Yusov, when creating an artistic image in the creative process, attached great importance to the imagination, which is the basis of creativity, a kind of form of realization of a person's dreams and aspirations. Differentiating the notions «imagination» and «creativity» the studier defines creativity as the business side of the artistic product, noting that the level of its external perfection depends on professional skills, and attributes to the imagination the property of the spiritual manifestation of a person in art, which forms the basis for the formation of his culture [4]. T.A. Koptseva while evaluating the children works pays great attention to such a criteria, as a harmonious unity of the manner and matter which defines the creative image [5].

V.P. Golovanov distinguishes the content of polyspheric development of additional education as the system of a personal-pragmatist sphere which among others includes arts specificity [6]. Yu.V. Vardanyan studies the different channels of acting and future teachers' exposure to studying, acquisition and the following appliance of the professional skills, emphasizing the need for «dissemination of innovative pedagogical experience among students and graduates of pedagogical educational institutions» [7].

In order to create an artistic image it is necessary to be ready to its implementation with the help of means of artistic expression. Thus, an artistic image in a painting is created by means characteristic to this particular type of the arts (colour, coloration, tonality, saturation, assemblage, etc.). Consequently, having its own peculiarities it differs from an artistic image in music and other types of the arts, but maintains the common features inherent in different types of creative activity. It is important for the future teacher-artist to have the readiness for creative activity, which is defined by us as («a special artistic and pedagogical competence of a student, the development of which provides orientation to the creation of a creative product (his/her own and by students supervised by him/her) and actions for its implementation, absorbing the willingness to express themselves in different aspects» $[8]$.

An artistic image is one of the universal categories of the artistic creativity in the artwork, fine art photography, musical art, literature, etc. The content of an artistic image is defined by the existing world reality, by the artist's reflection of the surrounding world, his worldview, life position or imagination as the embodiment of his own sensory-emotional states, visions, dreams, aspirations or hopes. This determines the relevance of the study of ways to form the readiness of students to create an artistic image and its implementation in creative activity in the process of performing an art composition. 


\section{Results of the research}

An artistic image creating is impossible without developed imagination, imaginative thinking, special vision, the formation of which is essential for further creative activity. In a particular type of art there are their own means of expression, forms and methods that contribute to the emotional representation of the surrounding world. The art exists not for the sake of representation, but for the sake of expressing feelings, thoughts, experiences, attitude to the depicted object. The implication is that the creative process itself serves as the basis for an art work creation, which supposes the possibility and ability for the creative artist to implement his/her ideas, thoughts which arose from an experienced event in the artistic image and encourage the audience to think and to enter in the dialogue with the author.

Studying the peculiarities of music images in the work of O.E. Pavlyukova and V.N. Tsarev we pointed out that the creation of an artistic image while teaching the children music school pupils to vocal-pop artistic performance is influenced by such factors as «the degree of voice proficiency, the harmony of the sound of a musical work», recreating the original artistic world of a musical work [9]. Yu.V. Velichko and others believe that the perception of music becomes a complex synthetic process «when there is an integration, external and internal interaction of artistic images of music and audiovisual images, audio, musical and visual images in structural and content unity» [10]. L.G. Parshina and O.F. Asatryan claim that in the process of multimedia projects creation during the extracurricular work music majors create musical videos which are based on «music visualization with the reflection of its image; representation of the means of musical expression with the help of animation» $[11]$.

L.A. Podocenov emphasizes, that an artistic image of a theatrical performance largely depends on the creative interaction of its two authors - the director and the artist [12].

This problem is particularly acute in the training of future designers, teachers and artists. T.V. Krasnova and M.B. Permyakov were studying the problems of an artistic image developing in the design and architecture and highlighted the role of the "personal" and "collective" contribution of developers to the creation of the design of the architectural environment [13]. In search of methodological approaches to taking into account the influence of the means of art education used in the university on the qualitative characteristics of the effectiveness of the training of the future teacher-artist for the organization of creative activities of students, V.A. Vardanyan and his colleagues find that «The main criterion for the student success during this period is the creative work of his pupils» [14].

The importance of art education is paid much attention to now. Revealing its pros and cons, G.B. Roege and K.H. Kim acknowledge that «Participation in arts education may not directly result in improved achievement on standardized tests» [15, p. 121]. Calling for increased access to art education, Sh.M. Malley and L.B. Silverstein encouraged to create a consortium of stakeholders in art education and special education communities to facilitate the artistic development of students with disabilities [16].

The experience of university training of specialists in the field of art education is of great interest for our study. S. Rodgers summarized the experience of organizing highquality preparation of a group of students for museum workshops [17].

M. Kunter and colleagues in their study used a variety of indicators to assess the competence of teachers, the quality of learning and student performance and their motivation [18]. On this basis, it was proved that the greatest impact on student learning outcomes is exerted by such professional competencies of teachers as knowledge of educational material, professional beliefs, motivation of professional activity and selfregulation. The work of $\mathrm{R}$. Stake and A. Munson highlights the features of evaluating art 
education and art programs in the process of teaching, training and educational management in the field of art, according to which quality is determined with an emphasis on observations and judgments, rather than on instruments and measurements [19].

The material for the study was the data of experimental testing of pedagogical conditions for the formation of students ' readiness to create an artistic image. The study involved 47 undergraduate students of the profile "Fine Arts" of the Mordovian State Pedagogical University named after M.E. Evseviev.

2 measurements were carried out, during which the level of formation of the components of their readiness to create an artistic image and the dynamics of changes were revealed. The educational test (test of knowledge of artistic terms and concepts, rules and techniques of composition, psychology of facial expressions and gestures that convey the emotional state of a person); observation (assessment of the application of artistic training in the creative process quality); the technique of "Horizon line" (identification of the focus on the creation of an artistic image) were used for that purpose. Methods of mathematical and statistical evaluation of the data, including the G-sign criterion, were also used to assess the shift in the values of the studied signs of readiness components.

Readiness implies a state in which everything is done so that the artist can start creative activity. We have identified the following components of readiness:

1. Cognitive (includes the knowledge of artistic terms and concepts rules and techniques of composition, psychology of facial expressions and gestures that convey the emotional state of a person; it arises under the influence of cognitive interest and the desire to perceive and express one's feelings based on the impressions received, to overcome difficulties in the creative process and to create an expressive image).

2. Pragmatist (based on the students ' mastery of the skills and abilities of depicting an expressive artistic image with various techniques and materials, and artistic and expressive means).

3. Emotional (it is expressed in a positive attitude to the artistic and creative process, the ability to give an objective assessment of the process and the degree of satisfaction with the result).

During the ascertaining stage of the experiment the present level of students ' readiness to create an artistic image was revealing. The identification of knowledge was carried out through testing. The determination of the level of the pragmatist component of readiness was based on long-term observation of the creative process, which was evaluated according to the following parameters:

- knowledge of painting techniques and techniques (watercolour, gouache);

- the ability to create a certain color scheme that expresses the emotional state in the work;

- expressiveness of the drawing, the ability to create an original plot, observing the rules of composition (choice of format, balance, compositional center, planning, movement, etc.).

The emotional component was checked using the "Horizon Line" technique proposed by A.A. Melik-Pashayev [20]. The analysis of the obtained empirical data shows that a small part of the students has a high level of readiness to create an expressive artistic image in the process of performing a plot-thematic composition (Fig. 1), while a significant number of students showed an average and low level of formation of the studied property (Figure 1). 


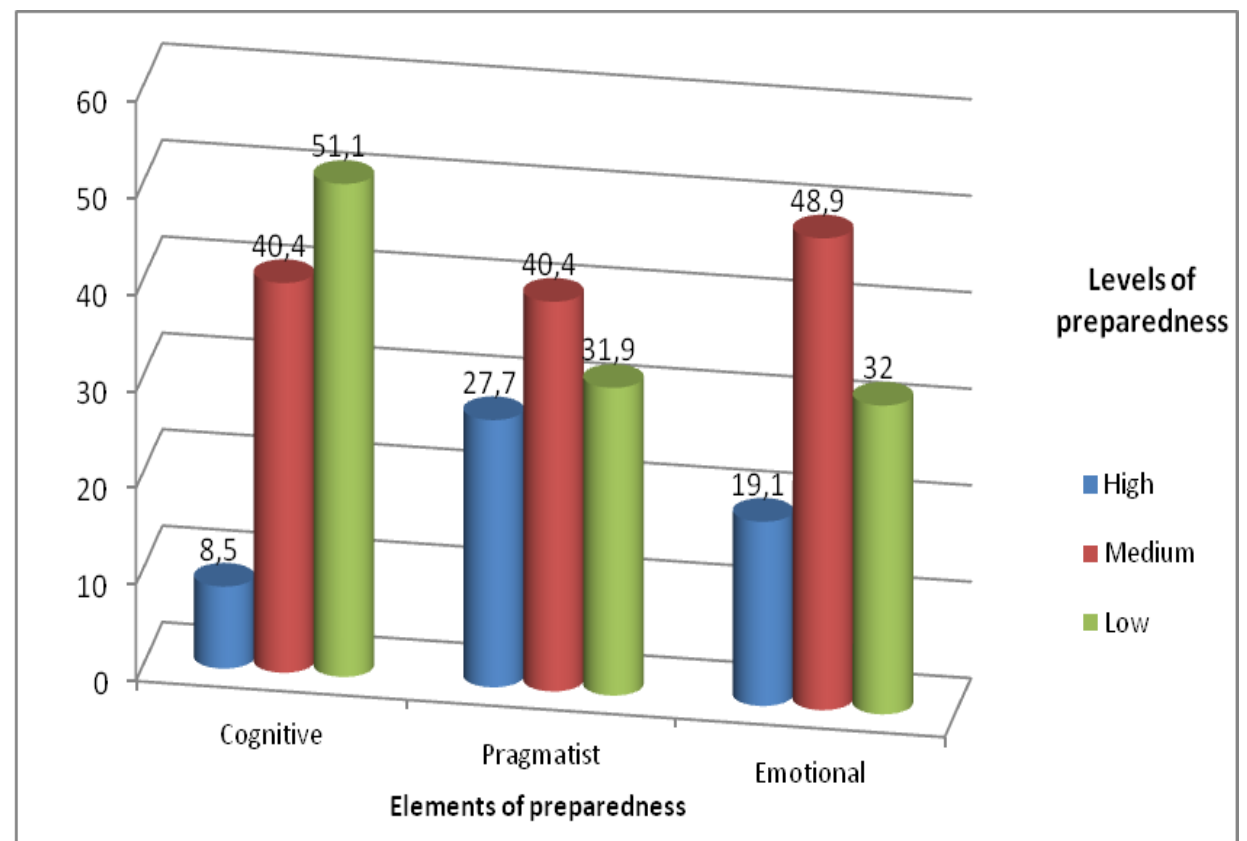

Fig. 1. The data of the assessment of the readiness components formation of children's art school students to create an artistic image at the ascertaining stage.

On the basis of data obtained we came to the conclusion that it is necessary to develop and implement into the educational process pedagogical conditions that contribute to the formation of students ' readiness to create an artistic image.

At the formative stage of experimental work, we tested the following pedagogical conditions:

a) cognitive interest formation;

b) emotional and figurative perception of objects and phenomena of the surrounding world development;

c) creating a situation of success in creative activity.

Cognitive interest formation was implemented by means of the creative search atmosphere creating, when the students together with the teacher are broadening their knowledge about the universal means of a bright and expressive image creation; are reflecting on the basics of creating a composition using color, texture, proportions, materials, volume, etc.; are discussing the semantic and visual center of the composition, the rules of linear, aerial perspective.

Extracurricular lessons aimed to develop artistic and imaginative thinking, observation, activation of attention; discussion of images and ways of their implementation: art history stories and conversations, visits to exhibitions, museums of fine art were organized. They got acquainted with the peculiarities of an artistic image creation in the creative activity of such artists as Mikhail Vrubel, Nikolay Feshin, Gustav Klimt, Andrei Mylnikov, Evsei Moiseenko etc.

The development of emotional and figurative perception of the surrounding reality presupposed the figurative embodiment of thoughts and feelings by pictorial means. Perceiving the objects of nature through emotions, students understand the world around them, comprehend the images of objects and convey them by artistic means (color, lines, shapes, contrast, texture, etc.). They were asked to perform a pictorial composition on the theme "Alone". This topic is relevant for young people, as this is a period of intensive, but uneven development in creative activity. For the successful implementation of the creative 
task, compositional searches were carried out, work was done from nature; work on sketches, and finally, the composition was made in color.

The creation of the situation of success in the creative activity was provided by taking into account individual creative abilities, tactful direction of search work on sketches, methodological support in choosing the plot and content, color solutions of the composition. It is necessary to motivate the success and the creative self-expression of each student, giving him/her the opportunity to creatively express his/her individuality.

After the completion of the painting composition, a reflection of the creative activity was carried out, which provided an understanding of the result of an artistic image creating. There was a review of the works, during which the students discussed the artistic image of each exhibited composition.

At the control stage of the experimental work, the cognitive component was tested again, the students were monitored to determine the level of the pragmatist component of their readiness to create an artistic image, and the "Horizon Line" technique was used to test the emotional component. The analysis of changes in the obtained data in comparison with the data of the ascertaining stage revealed a positive dynamics of the level of formation of all components of students ' readiness to create an artistic image in the process of performing a pictorial composition (Table 1).

Table 1. Data on the assessment of the dynamics of the formation of components of students ' readiness to an artistic image creation.

\begin{tabular}{|c|l|c|c|c|}
\hline \multirow{2}{*}{ Element } & \multicolumn{3}{|c|}{ Stage } & \multicolumn{3}{c|}{ Levels of preparedness (\%) } \\
\cline { 2 - 5 } & & high & middle & low \\
\hline \multirow{2}{*}{ Cognitive } & ascertaining & 8,5 & 40,4 & 51,1 \\
\cline { 2 - 5 } & control & 59,6 & 29,8 & 10,6 \\
\hline \multirow{2}{*}{ Pragmatist } & ascertaining & 27,7 & 40,4 & 31,9 \\
\cline { 2 - 5 } & control & 51,1 & 40,4 & 8,5 \\
\hline \multirow{2}{*}{ Emotional } & ascertaining & 19,1 & 48,9 & 32 \\
\cline { 2 - 5 } & Control & 51,1 & 48,9 & 0 \\
\hline
\end{tabular}

A quantitative analysis of the revealed changes in the components of the studied personality quality shows that the greatest positive changes occurred in the formation of the cognitive component. This is to a certain extent due to the concern of teachers about the development of the necessary content of art education, which is the basis for an artistic image creating. There were also marked changes in the quantitative composition of the owners of low and medium levels of activity and emotional components of readiness, which supplemented the number of owners of medium and high levels of readiness to create an artistic image at the control stage.

To assess the statistical significance of the changes that occurred, the G-sign criterion (Table 2) was used. A positive shift was considered typical.

Table 2. Data on the assessment of the relevance of the formation of components of students ' readiness to an artistic image creation.

\begin{tabular}{|c|c|c|c|c|c|c|c|c|}
\hline \multirow[t]{2}{*}{ Element } & \multirow{2}{*}{$\begin{array}{l}\text { Number } \\
\text { of zero } \\
\text { reactions }\end{array}$} & \multicolumn{4}{|c|}{ Number of moves } & \multirow[t]{2}{*}{$\mathbf{G}_{\text {эмп. }}$} & \multicolumn{2}{|c|}{$\mathbf{G}_{\mathrm{kp}}$} \\
\hline & & $\mathbf{n}$ & + & - & typical & & $\mathrm{p} \leq 0,05$ & $\mathrm{p} \leq \mathbf{0 , 0 1}$ \\
\hline Cognitive & 23 & 24 & 20 & 24 & 20 & 4 & 7 & 5 \\
\hline Pragmatist & 30 & 17 & 13 & 17 & 13 & 4 & 5 & 3 \\
\hline Emotional & 32 & 15 & 15 & 15 & 15 & 0 & 3 & 2 \\
\hline
\end{tabular}


The analysis of the data obtained using the G-sign test showed that the most significant shift in values was found when assessing changes in the cognitive and emotional components of readiness at a one-percent significance level. There were also significant changes in the pragmatist component of students ' readiness to create an artistic image at the five-percent level of significance.

Thus, the test of the effectiveness of the students' readiness formation to the artistic image creating in the process of pictorial art assemblage performing shows the effectiveness of the work carried out. Obtained data strongly signifies that the identified pedagogical conditions of students' readiness formation in the process of pictorial art assemblage performing are positively effective. Consequently, in order to make this process purposeful, it is necessary to first introduce the future teacher-artist to the creation of an artistic image and to master the methodological approach to the organization of the studied aspect of working with students in the upcoming professional activity.

\section{Conclusions}

Art education intensifies its significance due to the increasing opportunities to contribute to the process of creative development of the individual. This fact actualizes the necessity in the art-teaching staff creative development, capable of both developing culture and art and developing the younger generation by means of artistic and creative activity, which emphasizes the importance and prospects of solving a number of problems:

- substantiation of the potential of easel composition as a genre of art that focuses on the creation of an artistic image and creative achievements;

- substantiation of the potential of easel composition as a genre of art that focuses on the creation of an artistic image and creative achievements;

- determination of the essence of the readiness of the future teacher-artist to create an artistic image as a personally and professionally significant step-by-step forming special competence.

As a result of the research, a number of scientific and methodological products were created: differentiation of the features of the components of readiness for creative activity; the composition of the pedagogical conditions that contribute to the creation of an artistic image; characteristics of the stages of creating an artistic image in a painting; justification of the methodological approach to the pedagogical management of students ' work on the creation of an artistic image and its implementation by means of painting. The scientific and methodological products and methodological recommendations formulated in the course of the research enrich modern didactics, the methodology of higher art and pedagogical education and educational practice with new ideas and approaches to solving dynamically emerging problems.

\section{References}

1. E.K.Shapinskaya, N.I. Kiyashenko, Dialogue about aesthetic education: crisis of values and ways to overcome it, Culture and art, 4, 417-427 (2014)

2. Introduction to literary studies. Literary work: basic concepts and terms, Edited by L.V. Chernets et al, 556 (1999)

3. G.N. Pospelov, Esthetic and artistic, 405 (1998)

4. B.P. Yusov, About the interaction of arts in development of children in integrated classes. When all the arts are together: poliartistic development of students of different age groups: a guide for teachers, 108 (1995) 
5. T.A. Koptseva, Diagnostic tools for evaluating educational achievements of students: Features of analysis of drawings of children and adolescents, Pedagogy of art, 1, 143$150(2020)$

6. V.P. Golovanov, Polyspheric development of additional education of children in modern Russia, Bulletin of Tambov University. Series: Humanitarian Sciences, 4 (44), 527-532 (2006)

7. Yu.V. Vardanyan, Dissemination of innovative experience as a factor of modernization of pedagogical education, Higher education in Russia, 4, 86-91 (2013)

8. V.A. Vardanyan, N.V. Matveeva, A.P. Rusyaev, Exhibition activity as a means of art education of a future teacher-artist, Opcion, 34 (85), 2062-2076 (2018)

9. O.E. Pavlyukova, V.N. Tsarev, Creating an artistic image in a vocal variety work for students of the children's school of arts, Bulletin of the Tomsk state pedagogical University, 8 (185), 118-121 (2017)

10. Yu.V. Velichko, O.V. Militsina, S.V Shishkina, Musical and creative practice of children using audio-visual technologies in the conditions of additional education, The Humanities and Education, 11 (1), 17-21 (2020)

11. L.G. Parshina, O.F. Asatryan, Multimedia project as a means of organizing extracurricular work of students-musicians, The Humanities and Education, 10 (2), 102-108 (2019)

12. L.A. Podosenov, Interaction of a director and an artist in creating an artistic image of a theatrical performance, Bulletin of the Moscow state University of culture and arts, 1 (75), 122-130 (2017)

13. T.V. Krasnova, M.B. Permyakov, Technology of developing an artistic image in design and architecture by means of graphic design concepts, Modern problems of science and education, 1, 11 (2018)

14. V.A. Vardanyan, A.P. Rusyaev, N.V. Matveeva, Exhibition and project activity as a means of art education of the future teacher-artist, World of Science. Pedagogy and psychology, 6, [Electronic resource] https://mir-nauki.com/PDF/28PDMN619.pdf (2019)

15. G.B. Roege, K.H. Kim, Why We Need Arts Education, Empirical Studies of the Arts, 31 (2), 121-130 (2013)

16. Sh.M. Malley, L.B. Silverstein, Examining the Intersection of Arts Education and Special Education, Arts Education Policy Review, 115 (2), 39-43 (2014)

17. S. Rodgers, Toward a pedagogy for faculty and student coresponsibility in curating college museum exhibitions, Arts and Humanities in Higher Education, 14 (2), 150165 (2015)

18. M. Kunter, U. Klusmann, J. Baumert, D. Richter, T. Voss, A. Hachfeld, Professional competence of teachers: Effects on instructional quality and student development, Journal of Educational Psychology, 105 (3), 805-820 (2013)

19. R. Stake, A. Munson, Qualitative Assessment of Arts Education, Arts Education Policy Review, 109 (6), 13-22 (2008)

20. A. Melik-Pashaev, Z.N. Novlyanskaya, A.A. Adaskina, N.F. Chubuk, Artistic talent of children, its identification and development, 112 (2006) 